\title{
The Influence of Non-linguistic Factors on the Usage of the Pre-prefix in Luguru
}

\author{
Malin Petzell \\ University of Gothenburg
}

\author{
Karoline Kühl \\ University of Copenhagen
}

\section{Introduction}

This article discusses the impact of linguistic and non-linguistic factors on the use of the pre-prefix in an under-described Bantu language spoken in Tanzania. ${ }^{1}$ The pre-prefix, also referred to as the augment, is a morpheme related to givenness ${ }^{2}$ in many Bantu languages. We will explore its use in Luguru, which is spoken in the Morogoro region in Tanzania. While the pre-prefix occurs frequently in Luguru, it is barely used in most of the neighbouring languages, which is unexpected since the languages are highly similar when it comes to grammatical structure. What is more, certain groups of Luguru speakers use the pre-prefix much more than others, and its use seems to vary according to social settings. We present a sociolinguistic analysis of the contexts where the pre-prefix can appear, including attitudes and social factors, taking into account the situation of intense language contact between Luguru and the dominating language Swahili, where the preprefix is non-existent. Not much has been published on Luguru overall, and this is the first study of the pre-prefix. Moreover, it is, to our knowledge, the first work taking social factors into account in analysing the pre-prefix in Bantu in general.

We begin by sketching the sociolinguistic situation in section 2 , followed by data collection and method (section 3). Next we focus on the form and function of the pre-prefix (section 4), including evidence (or lack thereof) for its existence in Luguru and neighbouring languages (section 4.1) and a description of its linguistic function (section 4.2). In section 5, we turn to nonlinguistic and social factors such as evidence for language attitudes, both voiced by the speakers and conveyed implicitly through the speakers' linguistic practices. The attitudes that become visible in our data hint at the fact that the use of the pre-prefix in Luguru is considered part of "good" and correct Luguru. This is also what all informants say when asked - it is more "proper" language to use the pre-prefix. We consider this one of the reasons that the pre-prefix has not disappeared from present-day Luguru, despite the huge pressure that Luguru (like so many other minority or regional languages) is under from the dominant language, Swahili (see section 1.2). In the final section (6), we will demonstrate that notwithstanding all assumptions, the usage of the pre-prefix has remained stable, and we will analyse this (non-)accommodation as stability despite contact (Kühl and Braunmüller 2014) due to covert prestige.

The data in this study were gathered by the one of the authors during field trips to the Morogoro region in 2009, 2014 and 2016. They consist mostly of structured interviews and elicitation (including translation of wordlists, sentences and stories). We were also given copies of new Bible translation portions. Data was collected from a wide range of speakers with regard to productive and receptive language competence, orthographic knowledge and linguistic awareness (see section 2 ). This enables us to compare different speaker profiles when considering the occurrence of the pre-prefix in their speech.

\footnotetext{
${ }^{1}$ We are grateful to two anonymous reviewers for helpful comments and suggestions.

${ }^{2}$ Givenness is used here as a common term for the multiple aspects of referential status; see section 4.2.
} 


\section{Linguistic situation and background}

Tanzania is characterised by triglossia, which can be described using Bambgose's three-language model (1991: 54-58). Within the higher education system, English is used; the national language Swahili is understood by the whole population; while on a regional level and in the home, smaller African languages, such as Luguru, are spoken. These African languages are often referred to as minority languages, which means that they are restricted to a few non-formal domains and are subordinate to Swahili and English. Sometimes the speakers also constitute a minority numerically, but in seven cases, the number of speakers for a minority language in Tanzania is over one million. Estimates of the number of minority languages in Tanzania range between 124 (Lewis et al. 2015) and 164 (Languages of Tanzania Project 2009), depending on where the line between a dialect and a language is drawn.

Swahili is the largest language in Tanzania, as well as an official language, alongside English. The number of speakers of Swahili is unclear. Lewis et al. (2015) give the number 15 million with no explanation as to how they reached that result. The total population in Tanzania was 44,928,923 according to the 2012 population census (http://www.nbs.go.tz/), and Swahili is estimated to be understood and used by at least $90 \%$ of the population. That said, it is only the mother tongue of approximately $10 \%$ of the Tanzanian population (Rubagumya 1990). Swahili is a lingua franca with a supra-ethnic function, "thus facilitating the verbal interaction of people regardless of their ethno-linguistic origin" (Legère 2010). It is used throughout the country, even in the more isolated areas, and is an integral part of Tanzanian society. Most of the minority languages in Tanzania are Bantu languages, meaning that they are related but not mutually intelligible. The Bantu languages are the most substantial language group in Africa and constitute a subgroup of the Niger-Congo family. In total, there are about 500 Bantu languages, depending on how one counts (Schadeberg 2003: 143). The Bantu languages are divided into geographical zones following the alphabet, a system that was established by Malcolm Guthrie in the 1960s and 1970s. The languages spoken in the Morogoro region in Tanzania belong to a group called the G30 languages. Luguru (G35) is part of a dialect continuum which also includes Kami (G36), Kutu (G37), Kwere (G32) and Zalamo (G33). All these languages are mutually intelligible. Swahili (G42) is less closely related to these languages, but it is difficult to determine the actual level of intelligibility, since everyone is bilingual in their minority language and Swahili.

The Tanzanian minority languages are marginalised in the sense that they are not recognised by the state in domains such as public administration, education, health care or legal services. The general political climate discourages the use of the minority languages and promotes Swahili, as the minority languages are believed to undermine national unity and are considered retrogressive. Thus, they function first and foremost as markers of ethnicity and they operate as symbols of group solidarity. Speakers of minority languages are forsaking their languages for the social and economic benefits of Swahili (while retaining the group identity of the minority language). "Swahili threatens more than 130 other Tanzanian languages" (Brenzinger 2007: 196). The majority of people who do not speak Swahili in Tanzania are children who have not yet started school. Even if children do not speak Swahili to begin with, they must learn it in school since it is the medium of instruction in primary education. There is no bilingual education, which means that the students learn the language through submersion. This "sink or swim" approach to bilingualism is not unproblematic, and constitutes a burden in the children's learning (Wedin 2010: 145). But not only are the minority languages discouraged in school, they are stigmatised. Students and teachers are forbidden to speak the minority language during school hours and if they do so, they are punished in various ways. This stigmatisation is present all over the country. In some schools, the person who has broken the rule may have to wear a slate around their neck for the reminder of the day saying "Speak English or Swahili” Petzell 2013). 
In the Morogoro region, 16 minority languages are spoken alongside Swahili (Languages of Tanzania project 2009: 67). Kami is the smallest language in the Morogoro region, with a reported 5,518 speakers, and Luguru is the largest, with 403,602 speakers (Languages of Tanzania project 2009). In the smaller Morogoro district, Luguru speakers constitute $73.5 \%$ of the population (Petzell 2012b). Despite being the major language in the region, Luguru is restricted to a few domains of use, and its use is actively discouraged in schools and in other public contexts. There are high levels of Luguru-Swahili bilingualism, which is supported by the fact that Swahili is used as the language of education, the media, religion and politics. There is a brief published grammar of Luguru (Mkude 1974), as well as several articles written on certain phenomena; see for instance Marten and Ramadhani (2001) and Marten (2003). There is also an old grammar of Luguru, containing some elicited sentences (Seidel 1898); this contains no mention of the pre-prefix at all.

\section{Data collection, method and participants}

This survey is one outcome of two larger projects. The first project, "An analysis of a dialect continuum in the Morogoro region", languages in the region, including Luguru. The second project, "An analysis of an endangered language - the Kami in Tanzania", 4 constituted a description of the Kami language and its neighbours. The fieldwork was carried out over approximately 13 weeks in September-October 2009, February-March 2014 and July 2016. In-depth and/or group interviews were conducted with seven speakers, and four other speakers participated in shorter interviews and filled out questionnaires. Additionally, recordings were made for other purposes, such as detecting lexical and grammatical tones, and we were able to carry out several hours of participant observation, since we were living among the speakers.

All consultants were chosen on the basis of their linguistic competence, and all are L1 (mother tongue) speakers born in the area where the language is spoken. The speakers' linguistic competence was verified by other speakers of the language by simply asking "Is s/he a good speaker of ...?". That said, we wanted to include speakers from different social groups, with different levels of education and of both genders. This resulted in one illiterate (or semi-illiterate) consultant who proved to be excellent at linguistic judgement. She had help from another speaker or from the interviewer to write down any answers that were not recorded. Six speakers had college degrees and could speak English (meaning that they had learnt another language apart from Swahili and could reflect on linguistic differences, etc.). Out of the six educated speakers, four are trained Bible translators who work with language professionally. Apart from their outstanding linguistic competence in their native languages, they are trained to reflect on their linguistic choices and to discuss their language usage at a metalinguistic level.

Two main elicitation techniques were used - one a questionnaire consisting of approximately 450 sentences to be translated from Swahili, and the other a made-up story without an ending. The consultants were asked to translate the story but also to write the ending. The story was constructed so that it would contain many possibilities for the consultants to use the pre-prefix, but also to produce spontaneous speech/writing and to encourage the speakers to use their own words. As the pre-prefix is highly contextual and, unlike other nominal prefixes (such as the noun class prefixes), is dependent on discourse, sentences in isolation are not sufficient to capture this phenomenon.

The interviews were mostly conducted in Swahili and occasionally in English, usually with one consultant at a time. At times, group interviews were carried out, for instance with the Bible translators, which proved very fruitful. The group interviews contributed to quality control on data

\footnotetext{
${ }^{3}$ This project was funded by the Swedish Research Council.

${ }^{4}$ This project was funded by Riksbankens Jubileumsfond and the field trip by the Åke Wiberg Foundation.
} 
collection, and they helped the participants focus on the phenomena in question while allowing for animated linguistic discussions. The interviews began with the interviewer explaining what the project was about, i.e. to learn more about Luguru, and to try to extract a "pure" version of the language. Code mixing with Swahili is extremely common, but the consultants quickly became aware of this and tried to avoid it. The interviewer would typically ask in Swahili "(How) can you say this in Luguru?" and the consultants would answer in Luguru. We also asked sociolinguistic questions about the background of the consultants, their language preferences, whether they speak Luguru with their children, etc. An average interview would take three hours. Some consultants we only met with two or three times, and some up to eight times.

\section{The form and linguistic function of the pre-prefix}

The so-called pre-prefix consists of the initial segment, usually in the shape of a consonant and a vowel, which appears before the obligatory noun class prefix on nouns in many Bantu languages. It is reported that $60 \%$ of the Eastern Bantu languages make use of the pre-prefix in some form (Nurse and Hinnebusch 1993: 339). Especially when talking about South African languages, the pre-prefix may be called the augment, but since this may be confused with the term augmentative, that term is avoided here. In other Bantu languages, it may also be called the initial vowel, and in Luguru, the pre-prefix has been referred to as the specifier (Mkude 1974: 51).

Nouns in Luguru, as in many other Bantu languages, consist of a noun stem and one or two prefixes. The noun classes go back to an original Proto-Bantu ${ }^{5}$ system where singular and plural nouns are paired, meaning that the nouns in class 1 take their plural in class 2 , etc. The pre-prefix is optional in most settings, while the other two components (the noun class prefix and the noun stem) are integral constituents of any noun. The compulsory noun class prefix may, however, be realised as $\varnothing$, as seen for noun class 5 in Table 1 .

\footnotetext{
${ }^{5}$ Proto-Bantu is a reconstructed common ancestor of the current Bantu languages.
} 


\begin{tabular}{|l|l|l|l|}
\hline Noun & Pre-prefix & Noun class prefix & Agreement prefix $^{6}$ \\
\hline 1 & $i-$ & $m u-/ m w-$ & $y u-$ \\
\hline 2 & $i-$ & $w a-$ & $w a-$ \\
\hline 3 & $g u-$ & $m-$ & $u-$ \\
\hline 4 & $i-$ & $m i-$ & $i-$ \\
\hline 5 & $l i-/ d i-$ & $\varnothing / l i-/ d i-$ & $l i-/ d i-$ \\
\hline 6 & $g a-$ & $m a-$ & $g a-/ y a-$ \\
\hline 7 & $i-$ & $c h i-$ & $c h i-$ \\
\hline 8 & $i-$ & $p f i-/ f v i-$ & $v i-/ f y i-$ \\
\hline 9 & $i-$ & $N-/ \varnothing$ & $i-$ \\
\hline 10 & $n z i-$ & $N-/ \varnothing$ & $z i-$ \\
\hline 11 & $(i-)$ & $l u-/ r u-$ & $l u-$ \\
\hline 14 & - & $u-$ & $u-$ \\
\hline 15 & $(u-)$ & $k u-$ & \\
\hline 16 & $i-$ & $h a-$ & $h a-$ \\
\hline 17 & - & $k u-$ & \\
\hline 18 & - & $m-$ & \\
\hline
\end{tabular}

Table 1: Noun class prefixes in Luguru

Both prefixes - the obligatory nominal class prefix and the non-obligatory pre-prefix - are exemplified in (1) below. Note that tones are not distinctive in meaning in Luguru; consequently, we do not mark tones in the examples in this paper.
(1)

\begin{tabular}{|c|}
\hline $\begin{array}{l}\underline{i} \text { chinu } \\
\text { í-chi-nu } \\
\text { PPX-7-thing }\end{array}$ \\
\hline this thing' \\
\hline
\end{tabular}

Although the pre-prefixes in Table 1 above are from Luguru, the form is fairly similar in the other Bantu languages where it exists. In the G group, the pre-prefix is usually in the shape of a single vowel, hence the alternative name initial vowel. Originally, it was most likely a CV construction

\footnotetext{
${ }^{6}$ These agreement prefixes are also called pronominal prefixes and mark agreement on other constituents in the noun phrase. They are included here since they are believed to be the origin of the current form of the pre-prefixes.

${ }^{7}$ The number refers to the noun class. PPX= pre-prefix. DEM= demonstrative.
} 
in all classes consisting of the agreement (pronominal) prefix (de Blois 1970: 153), which is still the case in Luguru's class 6 for example: e.g. ga-ma-bwende 'clothing'. In other classes, the former agreement prefix has been reduced to a vowel in Luguru, as seen in $\underline{\boldsymbol{i}}$-chi-nu 'thing'. Hyman, likewise, suggests that the pre-prefix is in the shape of the agreement prefix since, in Bantu, they both historically carry a high tone like the pre-prefix (Hyman p.c. 2005).

In many Northeast Coastal Bantu languages ${ }^{8}$, the vowel that is left (from the CV-construction) has been replaced with $i$ - in classes 1, 2 and 16 (Nurse and Hinnebusch 1993: 339); this is also the case for Luguru. The process has gone further since Nurse and Hinnebusch's data were collected, and $i$ - has now replaced $u$ - in class 11 as well. In some classes in Luguru, the full CVC(V) form is still retained, as seen in class 3 (gu-m-tego 'trap') and class 6 (ga-ma-tunda 'fruits'). Classes 5 and 10 also have a CV pre-prefix, but since they have a merged (or zero) regular prefix, we believe the pre-prefix and the regular prefix may be conflated. This is corroborated by Guthrie, who states that a double prefix (either augmented by a single $\mathrm{V}$ or a $\mathrm{CV}$-construction) is unusual for class 5 in general (1948: 12). The pre-prefix of class 5 nouns being treated as the regular class prefix is found in other Bantu languages as well, such as Kwangali (Legère 2005: 259). Metathesis between the pre-prefix and the noun class prefix of class 5 is also described for other Bantu languages (Ngunga p.c. 2003).

\subsection{Evidence (or lack thereof) for the existence of the pre-prefix in Luguru and its neighbouring languages}

As mentioned above, the pre-prefix is attested in Proto-Bantu and particularly in Proto Northeast Coastal Bantu (Nurse and Hinnebusch 1993: 340). However, in the Luguru sources from the $19^{\text {th }}$ and early $20^{\text {th }}$ century, there is not a single pre-prefix, neither in the historical grammar sketch nor in the historical elicited sentences (both by Seidel 1898) (see Table 2 below). The very first mention of a pre-prefix in Luguru (apart from in reconstructed Proto Northeast Coastal Bantu) is in 1948 (Guthrie ), although Guthrie is not clear on who his source is, and the reliability of the data cannot be confirmed (Guthrie 1948: 8). The next time the pre-prefix is mentioned is in Mkude's (1974) grammar. The fact that the pre-prefix in Luguru was missed or ignored ${ }^{9}$ by all missionaries working with the language is highly unlikely. We have to assume rapid language change, and that the preprefix could have arisen on more than one occasion (Guthrie 1967/71: 229). We thus postulate the existence of a pre-prefix in Proto Northeast Coastal Bantu, almost 2000 years ago (Nurse and Spear 1985: 40), then no pre-prefix in the $18^{\text {th }}$ and $19^{\text {th }}$ centuries, and then a reintroduction of the preprefix in Luguru at the beginning of the $20^{\text {th }}$ century. This type of rapid change is attested in the neighbouring language Zalamo. In Zalamo, the pre-prefix is found occasionally in Klamroth (191011), and documented in the 1960s (Nurse and Philippson 1975), but is not found in more recent data (Petzell 2013); it was considered to be on its way out already in the 1980s (Nurse and Hinnebusch 1983: 340). Another neighbouring language, Kagulu, has a pre-prefix today which was also reported (in anthropological accounts) in the $1950 \mathrm{~s}-1970 \mathrm{~s}$, but there is no mention of the preprefix in the grammar of 1886 (Last 1886) nor any occurrences in the Book of Hymns dated 1894 (SPCK 1984). The same holds true for neighbouring Kami - there is no pre-prefix in the grammar and word list by Velten (1900) - but that is less of a puzzle since it is not attested in Kami today (Petzell and Aunio forthcoming). Table 2 below summarises these findings on the existence and reintroduction of the pre-prefix in Luguru and the neighbouring Bantu languages.

\footnotetext{
${ }^{8}$ I.e. Guthrie's zones E and G.

${ }^{9}$ There is a possibility that the missionaries were trained in Swahili and not accustomed to looking for pre-prefixes. For example, today we find gumage 'knife', whereas in 1898 only mage 'knife' is attested (Seidel 1898: 447).
} 


\begin{tabular}{|l|l|l|l|}
\hline Type of source & Kagulu & Luguru & Zalamo \\
\hline $\begin{array}{l}\text { historical } \\
\text { grammar sketch }\end{array}$ & No (Last 1886) & No (Seidel 1898) & $\begin{array}{l}\text { Occasionally (Klamroth } \\
1910-11)\end{array}$ \\
\hline $\begin{array}{l}\text { historical elicited } \\
\text { sentences }\end{array}$ & - & No (Seidel 1898) & - \\
\hline Johnston (1919) & No & No & No \\
\hline Guthrie (1948) & Yes & Yes & - \\
\hline De Blois (1970) & Yes & Yes & Yes \\
\hline Nurse (1970s) & - & Yes & Yes \\
\hline $\begin{array}{l}\text { modern grammar } \\
\text { sketch }\end{array}$ & Yes (Petzell 2008) & Yes (Mkude 1974) & - \\
\hline modern usage & Yes & Yes & No \\
\hline
\end{tabular}

Table 2: Mention of the pre-prefix in literature on neighbouring languages

As mentioned in section 2 above, the linguistic situation in the Morogoro region is characterised by the existence of the societally dominating supra-local and high prestige language Swahili, leading to a pervasive bilingualism (or multilingualism) with Swahili as one of the languages. The use of the low prestige-minority languages is restricted to certain domains. Under such circumstances, one would expect the minority languages to converge structurally with Swahili. Accordingly, Mkude reports that the pre-prefix was used mainly by older speakers in the 1970s (Mkude p.c. 2004; Mkude 2011). He attributes its use only by older speakers to influence from Swahili, i.e. that younger speakers in the 1970s had developed a simplified system due to accommodation to Swahili, where the pre-prefix is non-existent.

Consequently, Mkude claims that there is a tendency to drop the pre-prefix altogether in "present day" Luguru (Mkude p.c. 2004), and in a relatively recently printed leaflet containing classic Luguru tales where the storytellers are mostly older village people, the pre-prefix is used only very little (Lukanza et al. 2001). This supports Mkude's observations, as the younger speakers of the 1970s are the older speakers of today. What is more, Mkude states that when the pre-prefix is used, semantic distinctions are being neutralised (2011: 129). He goes on to write: "It is obvious that knowledge of Swahili is responsible for accelerating this simplification or blurring process" (Mkude 2011: 129). While his conclusion is that the pre-prefix is being used less and less, our observations state the opposite: the pre-prefix is used more frequently than ever in Luguru, despite being absent in Swahili and less used in the neighbouring minority languages. This kind of sharp demarcation between neighbouring languages is not seen elsewhere in the area, which is characterised by a dialect continuum. For instance, Luguru's neighbouring language Kagulu makes less use of the pre-prefix than Luguru, and Kagulu's neighbouring language on the other side, Ngulu, even less. ${ }^{10}$ So while we would expect usage of the pre-prefix to decline or even cease, the

\footnotetext{
${ }^{10}$ The unusual situation of Ngulu was noted in 1970: "It is somewhat strange because the neighbouring languages Ruguru (G35) and Kutu (G37) both have the augment" (De Blois 1970: 97).
} 
opposite seems to be the case for Luguru, not least because the historical development of Luguru, according to Mkude, and the development of neighbouring languages, suggest a diminishment in its use. However, in our data, we see that the pre-prefix is stable in contemporary Luguru in all source types, i.e. sentences, stories, interviews and participant observation. Its usage is at its highest in Bible translations. This certainly deserves an explanation.

\subsection{The linguistic function of the pre-prefix}

The pre-prefix varies in function and has different motivations among the Bantu languages in which it occurs. In typological work on Bantu, such as that of Greenberg, the pre-prefix is regarded as a typical non-generic article, in that "it is [+specific], that is, it involves an existence assumption and can in general be replaced by 'a certain"” (Greenberg 1978: 55). The seminal, albeit dated, work on the pre-prefix by de Blois states that it had a determinative function in Proto-Bantu, "which became less prominent in later stages" (de Blois 1970: 152). Van de Velde writes, "The augment is the default marker for reference in many Bantu languages, but can be replaced by other determiners" (van de Velde 2005: 439).

All of these functions are indeed found in Luguru. The pre-prefix is related to specificity, it can be determinative and it is a reference marker, and we thus propose that the pre-prefix in Luguru is related to givenness. The pre-prefix is more frequently used when the noun phrase is not in the scope of focus, i.e. it is used for given information and "determined by the vague concept of presupposition" (Mkude 1974: 108). It is probable that a noun that carries a pre-prefix is more extensive in referentiality ${ }^{11}$ and topicality. ${ }^{12}$ This is attested in other Bantu languages in the region, such as Bena (Morrison 2011: 164).

Givenness is used here as a common term for the multiple aspects of referential status. It also relates to familiarity and identifiably. Newly introduced information can still be familiar to both the hearer and the speaker (e.g. your wife) and an indefinite can still have been mentioned before in discourse (Would you like a banana? Yes, I would like a banana). As a marker of givenness, the pre-prefix can have a deictic function, as suggested by Nurse (1970s). Givenness can also be encoded by other items than the pre-prefix, usually by the use of pronouns such as demonstratives or possessives. Even though the pre-prefix is often used for definiteness and specificity, we also find it on indefinite, unspecified nouns, such as in the Luguru sentence Kukwela imwehe kunoga 'Marrying a wife is good.' In this proposition, however, the concept of 'a wife' (female person, belonging to a husband after a marriage ceremony, having certain rights and duties, etc.) might be familiar enough to involve givenness. A typical usage of the pre-prefix in Luguru can be seen in example (2) below. In the first phrase, a man is introduced; then, with the help of the pre-prefix, he is referred to again.

Aho mwande, tsahane munu. Ayo imunu tsakane mwehe.

'Once (upon a time), there was a person. This person had a wife.'

In the Bantu languages that do not make use of the pre-prefix, there is no other single morpheme with the same function. As an alternative, a demonstrative may be used, as seen in the equivalent phrase in Swahili Huyu mtu, alikuwa na mke 'This person had a wife'. Interestingly, the same type of demonstrative not only occurs but can even co-occur with the pre-prefix in Luguru, which seems to point to some semantic bleaching of the pre-prefix (see Mkude 2011). Such co-occurrences are

\footnotetext{
${ }^{11}$ Defined by Crystal (1985:260) as: "to state a relationship of identity which exists between grammatical units in the discourse".

12 "the person or thing about which something is said or "the psychological subject"” (ibid: 311 ).
} 
reported for other Bantu languages well (see van de Velde 2005), but in those cases the demonstrative usually follows the noun, while in Luguru, the demonstrative may precede the noun and be immediately followed by a pre-prefix, as seen in ayo ifisi 'this hyena'.

The modern Luguru Bible translation shows both a use of the pre-prefix that clearly seems to be motivated by givenness, as well as a use that seems to be more random. For instance, the preprefix appears to be obligatory for the word 'person', even when there is no apparent association with topicality or referentiality. Similarly, the pre-prefix is always used on the word for 'God' munu, with only two exceptions (in total, 301 occurrences of $m u n u$ ). This seems to fit well with the function of the pre-prefix to express referentiality, since 'God' is highly referential (the single Christian god, not 'a god'). The same pattern is found in the usage of the pre-prefix on the word for 'king', mndewa. It occurs a few times without pre-prefix, but mostly when referring to kings other than Jesus Christ. When used for 'Christ', the word usually carries the pre-prefix. The difference in usage is illustrated in the sentence in (3).

\section{(3) Kawaghoma kuliha kodi kwa mndewa wa Roma, kuya kolonga yeye iyo Kiristu, imndewa. \\ 'He opposes payment of taxes to Caesar and claims to be Messiah, a king.'}

In (3), there is no pre-prefix when discussing the king of Rome, but for referring to Jesus Christ, even though the English version says 'a king' in the indefinite form, there is a pre-prefix in Luguru, meaning that we know which king it is referring to.

While it may be problematic to describe all the instances where the pre-prefix may occur, it is less problematic to state where it is not allowed (or dispreferred). In his 1974 grammar sketch, Mkude mentions four contexts where the pre-prefix was disallowed, certain interrogative constructions being one of them. This is in fact the only context in our data where the pre-prefix is not used, not even by the Bible translators. This confirms that, in Luguru, the pre-prefix is dispreferred with certain interrogative constructions, e.g. *Inganda yachi? 'Which/what house?' should read Nganda yachi? 'Which/what house?'

Another context where the pre-prefix should not appear, according to Mkude (1974: 110), is following the invariable element chila 'every'. Yet in our Bible data, chila 'every' co-occurs with the pre-prefix approximately half of the time. In an interview with an educated speaker who is not a Bible translator, he stated that the chila rule is still valid today. This was also corroborated by other speakers and by participant observation. The speaker did not produce any sentences with chila + pre-prefix, nor did he accept the ones we produced for his judgement.

Together with the rather unfocused use of the pre-prefix in combination with e.g. munu 'person' (unfocused with respect to preferentiality and topicality), we believe that this "systematic neutralisation of the semantic distinction conveyed by the specifier" (Mkude 2011: 129) has paved the way for the frequent usage we see in our data today. When asked to explain the chila + preprefix violation in the Bible translation, the speaker said that the Bible translators probably know more about Luguru than he does and that they use a more correct language. It is comments such as this that have led us to believe that the use of the pre-prefix in Luguru today is due to its function as a marker of "good" and "pure" Luguru, as opposed to Luguru influenced by Swahili (see the discussion in section 5 below).

\footnotetext{
${ }^{13}$ Furthermore, the demonstrative is proposed as the ultimate origin for the CV construction that eventually became the pre-prefix, although it has supposedly gone through several stages (Greenberg 1978: 47-82).
} 


\section{Non-linguistic factors influencing the use of the pre-prefix in Luguru}

Apart from the motivated marking of givenness by the use of the pre-prefix in Luguru, there seem to be non-linguistic factors that influence and contribute to its usage (or non-usage). In this section, we focus on some social factors that are relevant for explaining its usage.

In the new Luguru Bible translation ${ }^{14}$ made by younger speakers (in their early thirties), the preprefix is seriously overrepresented. In fact, most nouns in this Bible translation carry a pre-prefix: we even find it in phrases such as ne ipfinu 'with things', where an underlying trace of a pre-prefix in the $n e(n a+\underline{i}=n e)$ is usually sufficient. The translators admitted to adding the pre-prefix to their translated texts during their editing work. They would go through the translated Bible verse together several times, correcting the Luguru and often adding the pre-prefix. When asked why they did this, they said that it is more "proper" Luguru to do so and that to skip it is "sloppy". One of them said "the elderly understand better if you say imwana "child' instead of mwana "child". This seems to imply that the overuse of the pre-prefix by the translators in the Bible translation comes about through hypercorrection. There are further examples of speakers adding pre-prefixes when correcting themselves to speak more properly. In an interview with an older Luguru lady she says mulume wangu 'my husband', and then when asked to repeat it she says umulume wangu 'my husband' with the pre-prefix. Such behaviour, i.e. speakers correcting themselves to speak more properly, is not uncommon during data collection, especially when the speakers are aware that the language is being documented (Marten and Petzell 2016).

Interestingly enough, the Bible translators mentioned above barely used the pre-prefix in the sentences and stories that they were asked to translate into Luguru as part of our data collection. Table 3 below is a table contrasting the translation of a story in Luguru by the Bible translators, a student and an illiterate woman. The Swahili story was created by one of the authors of the present paper with the purpose of generating pre-prefixes. Occurrences of the pre-prefix are marked in bold.

\footnotetext{
${ }^{14}$ The translators base their translation on three different versions of the Swahili Bible.
} 


\begin{tabular}{|c|c|c|}
\hline $\begin{array}{l}\text { Bible translators (in their } \\
\text { mid-thirties) }\end{array}$ & Student (30 years) & Woman (57 years, illiterate) \\
\hline $\begin{array}{l}\text { Haho ghumwande tsakukala } \\
\text { na muпu yumwe. }\end{array}$ & $\begin{array}{l}\text { Ghumwande dza } \\
\text { kukalemmale yumoja. }\end{array}$ & Aho mwande, tsahane munu. \\
\hline $\begin{array}{l}\text { Munu ayo tsakakala na } \\
\text { ipinga. }\end{array}$ & $\begin{array}{l}\text { Imale yo dza kana pinga } \\
\text { wake. }\end{array}$ & Ayo imunu tsakane mke. \\
\hline $\begin{array}{l}\text { Pinga ayu tsakanoghela } \\
\text { kuhanda tsimbeghu. }\end{array}$ & $\begin{array}{l}\text { Ipinga yo akaropenda } \\
\text { ukuhanda dzimbeghu. }\end{array}$ & $\begin{array}{l}\text { Imke yuno tsakapenda } \\
\text { ukuhande imbegu. }\end{array}$ \\
\hline $\begin{array}{l}\text { Chila litsuwa tsayang'ali } \\
\text { yohanda tsimbeghu. }\end{array}$ & $\begin{array}{l}\text { Shira siku akariohanda } \\
\text { dzimbeghu dzo. }\end{array}$ & $\begin{array}{l}\text { Chila siku tsakaliohanda } \\
\text { imbegu. }\end{array}$ \\
\hline $\begin{array}{l}\text { Yeye tsakakala kohanda } \\
\text { tsimbeghu pfinoghile. }\end{array}$ & $\begin{array}{l}\text { Shira mbeghu akaroihanda } \\
\text { ghoyaghoya. }\end{array}$ & $\begin{array}{l}\text { Imtwa tsakaliohanda chila } \\
\text { mgebu lugaluga. }\end{array}$ \\
\hline $\begin{array}{l}\text { Kuya tsakafsa munu yungi } \\
\text { tsakatsa, kalonga: }\end{array}$ & $\begin{array}{l}\text { Kuya imunu yungi kadza. } \\
\text { Kalonga: }\end{array}$ & $\begin{array}{l}\text { Kuya tsakatsa munu yungi. } \\
\text { Imunuyo tsakalonga: }\end{array}$ \\
\hline $\begin{array}{l}\text { "Sina nihande mbeghu } \\
\text { yoyose." }\end{array}$ & $\begin{array}{l}\text { "Sina nihande mbeghu } \\
\text { dzodzose bae" }\end{array}$ & $\begin{array}{l}\text { "Tsasinaniwahi ukuhanda } \\
\text { mbegu yoyosi." }\end{array}$ \\
\hline $\begin{array}{l}\text { Kuya yula imunu na } \\
\text { mwanduso kalonga: }\end{array}$ & Imunu wa kwanza kalonga: & $\begin{array}{l}\text { Kuya imunu yula wa } \\
\text { gumwanzo tsakalonga: }\end{array}$ \\
\hline $\begin{array}{l}\text { "Sitsohanda imbeghu yoyose } \\
\text { mne ughima wangu." }\end{array}$ & $\begin{array}{l}\text { "Sidzokala nihande mbeghu } \\
\text { bae mbaka nakufa." }\end{array}$ & $\begin{array}{l}\text { "Sihanda imbegu yoyosi } \\
\text { ning'ali mgima." }\end{array}$ \\
\hline $\begin{array}{l}\text { Pinga wake kalonga, "lekeni } \\
\text { atsino mbeghu itsimoghile } \\
\text { ng'ani”. }\end{array}$ & $\begin{array}{l}\text { "Dhimbeghu dzino maalum" } \\
\text { Kalongepinga. }\end{array}$ & $\begin{array}{l}\text { "Leke ino imbegu imanyike" } \\
\text { ipinga ayula tsakalonga. }\end{array}$ \\
\hline Bahala kalawila fisi. & $\begin{array}{l}\text { Dza wakale ifisi nae } \\
\text { kalawira. }\end{array}$ & $\begin{array}{l}\text { Maa weduka matsakalawila } \\
\text { mdewa fisi. }\end{array}$ \\
\hline $\begin{array}{l}\text { Hayu fisi tsakakala keha kwa } \\
\text { ukwiba tsimbeghu itsinoghile. }\end{array}$ & $\begin{array}{l}\text { Ifisiyo keha kwokwiba } \\
\text { dzimbeghu maalum. }\end{array}$ & $\begin{array}{l}\text { Ifisi yuno tsakane itabia iha } \\
\text { yo kwiba imbegu imanyika. }\end{array}$ \\
\hline $\begin{array}{l}\text { Imwanu wano weli na pinga } \\
\text { yula wose tsawalonga } \\
\text { hamwe: }\end{array}$ & $\begin{array}{l}\text { Iwamale weri wala nepinga } \\
\text { wose walongera lumwe: }\end{array}$ & $\begin{array}{l}\text { Iwalumewo iweli nae imke } \\
\text { wose walonga: }\end{array}$ \\
\hline $\begin{array}{l}\text { In total: } 8 \text { occurrences of } \\
\text { pre-prefix }\end{array}$ & $\begin{array}{l}\text { In total: } 11 \text { occurrences of } \\
\text { pre-prefix }\end{array}$ & $\begin{array}{l}\text { In total: } 14 \text { occurrences of } \\
\text { pre-prefix }\end{array}$ \\
\hline
\end{tabular}

Table 3: Translation of created story

[English translation: 'Once there was a man. This man had a wife. This wife liked to sow seeds. Every day she planted these seeds. She carefully planted each seed. Then another man came. He said "I have never planted any seeds". Then the first man said: "I will never plant any seeds as long as I live". "But these are special seeds", the wife said. Then suddenly Mr Hyena came. This Hyena was notorious for stealing the special seeds. These two men and that woman they all said:...']

The quantitative difference between the numbers of occurrences produced by the Bible translators (8) and by the illiterate women (14) is salient. This pattern was repeated in 2016, when two other Bible translators were asked to translate some sentences in which the pre-prefix occurred four times, compared to a student who used the pre-prefix nine times in the same sentences. It is clear that the Bible translators use the pre-prefix less than other speakers when they produce texts that are not translations of the Bible. 
An intuitive explanation that lends itself is that the situation was probably quite formal for the illiterate woman, especially as her spoken translations were written down (by one of the authors) and thus turned into a lasting document. The same goes for the student, who probably felt he was being tested. Although all three situations involved the same texts and the same interviewer, the degree of formality can be perceived as being quite different for the different participants. The illiterate woman and the student felt that a marking of formality or correctness was appropriate, while the translation task was very informal for the Bible translators and needed no editing. By comparing the linguistic practices of these speakers in different situations (Bible translation and the translation task for the data collection), it becomes evident that the frequent usage of the preprefix by the Bible translators can be explained by hypercorrection, which in turn has been facilitated by semantic bleaching of the pre-prefix (cf. Mkude 2011: 129 and section 4.2.). The hypercorrection hypothesis is further corroborated by the fact that the Bible translators violate two of the four "disallowed" rules designated by Mkude (1974), while the same two rules are upheld by most of the other informants.

\section{Discussion and conclusion}

This paper has discussed several factors that are relevant for the use of the pre-prefix in Bantu languages in general and, more specifically, in Luguru. Givenness (referentiality and topicality) is certainly a linguistic factor that determines the occurrence of the pre-prefix in Luguru. However, a similar function is fulfilled by the use of a demonstrative, sometimes together with a pre-prefix. Thus, there seems to be no context where the pre-prefix is absolutely mandatory, although there are some contexts where it is very likely to appear. Regarding Mkude's predictions with regard to contexts where the pre-prefix is disallowed, only two contexts are respected by most of today's speakers (as represented by our data). Further, the pre-prefix is often (over)used with no obvious connection to referentiality or topicality, especially by translators of the Bible. This shows a linguistically unfocused usage of the Luguru pre-prefix.

The partial semantic bleaching that seems to explain the unfocused use of the pre-prefix may be attributed to the linguistic situation in the Morogoro region and the intense contact between Luguru and the dominant lingua franca, Swahili, which has no pre-prefix. Even though Luguru is the regionally dominant variety, with approximately 400,000 speakers, Swahili is the supra-local and supra-ethnic variety, which is used in all public domains, thus creating a distinctive situation of diglossia characterised by a prestige gradient. Taking this prestige distribution into account, one would expect Luguru to converge towards Swahili and lose the pre-prefix altogether. However, despite the intense contact between Luguru and Swahili, the bilingualism of Luguru speakers, the societal dominance of Swahili in public life, writing, school, church etc., and the government's active discouragement of the use of minority languages, contemporary Luguru has not lost the preprefix. This linguistic stability deserves an explanation. We think that the stability of the pre-prefix in Luguru, despite intense contact, is best explained by a combination of both language-internal and language-external factors. Firstly, although the actual rules, i.e. the structural criteria for the application of the pre-prefix in Luguru are still vague in terms of academic description, the preprefix certainly expresses givenness in a way that is recognised by the speakers. This can be seen by the way the consultants actively manipulate it in the translation task and in the way that the Bible translators consciously apply it in the editing process. This implies that the pre-prefix does have a semantic-pragmatic function which justifies its continued existence.

Secondly, the conscious handling of the pre-prefix by the consultants reveals that they have particular attitudes towards this specific linguistic feature. Their attitudes are displayed both through metalinguistic comments and their actual linguistic practices. These practices seem to hint that the use of the pre-prefix is perceived as "good" and correct language, although its actual usage 
might not be gramatically correct. That, in turn, implies that Luguru speakers have specific views on good and bad Luguru language use.

This leads us to the thought that the maintenance of the pre-prefix in Luguru is a symptom of conscious divergence from neighbouring languages or dialects, and especially from Swahili. This phenomenon was recognised as early as 1917 and was termed "neighbour opposition" by the Norwegian linguist, Amund B. Larsen, when he described salient diverging features between two neighbouring Norwegian dialects (Larsen 1993). In Larsen's definition, the notion of "neighbour opposition" applies when one finds forms in a language variety which are not historically predictable and which function to make the distance from a neighbouring variety greater than would otherwise have been the case. The notion of "neighbour opposition" was developed further by Trudgill (2003), describing the attempt of speakers of one variety to adopt features from another variety, but overdoing it, "overgeneralising from correspondences they have noticed between the two varieties" (Trudgill 2003: 59). Trudgill terms the hyperadaptation process towards the High Variety "hypercorrection" (Trudgill 2003: 59-60), and the hyperadaptation process towards nonstandard dialects, which results in "constructions typical of older forms of the dialect", "hyperdialectism". The latter might occur as the result of neighbour opposition, "when dialect speakers overgeneralise differences between their own and neighbouring dialects in order to symbolise their different identities" (Trudgill 2003: 60).

However, neither the concept of "neighbour opposition" nor the concept of hyperadaptation exactly fits the situation in question. The speakers of Luguru are not developing any new features, nor do they overuse salient older forms ("hyperdialectisms"), and they do not adopt features from Swahili ("hypercorrections") (at least not features that mark givenness). The pre-prefix is an established feature of Luguru and has not come into existence as a product of the speakers' desire to accentuate the differences from Swahili. However, the fact that the pre-prefix is kept stable in Luguru might very well be the result of a conscious non-accommodation of Luguru speakers to Swahili, thus emphasising the divergence between the two languages. (Non-)accommodation of speakers refers to interactional norms and is as such best described in terms of social psychology (cf. Giles and Coupland 1991). The motivation for the differentiation between Luguru and Swahili, as represented by the use of the pre-prefix, seems to build on the covert prestige of Luguru. Crystal describes covert prestige as follows: "in covert prestige, forms belonging to vernacular dialects are positively valued, emphasizing group solidarity and local identity. This kind of prestige is covert, because it is usually manifested subconsciously between members of a group, unlike the case of overt prestige, where the forms to be valued are publicly recommended by powerful social institutions." (Crystal 2003: 115). Kühl and Braunmüller comment on the effect that covert prestige can have in language contact situations: "Much of the research on dialect convergence and divergence has been based on the basic assumption that divergence is caused by convergence towards a language with higher (overt) prestige and that divergence turns out to be divergence from a low-prestige variety. [...] the prestige relationship between languages or intra-lingual varieties is not necessarily the same throughout all linguistic domains. A specific language (use) can be highly prestigious in one situation and, thus, lead to convergence towards it. In another situation, the same language (use) may be considered inappropriate, and speakers will, therefore, diverge consciously from it" (Kühl and Braunmüller 2014: 20). The notion of covert prestige seems appropriate to describe the status of Luguru in the Morogoro region with regard to the intra-lingual prestige differences between Swahili and Luguru. Consequently, the stability in the use of the preprefix in Luguru can be described as stability despite contact (cf. Kühl and Braunmüller's framework (2014: 31-32). 


\section{References}

Bamgbose, Ayo. 1991. Language and the nation: the language question in sub-Saharan Africa. Edinburgh: Edinburgh University Press.

Brenzinger, Matthias. 2007. Language diversity endangered. Trends in linguistics. Studies and monographs. Berlin, New York: Mouton de Gruyter.

Crystal, David. 2003. A dictionary of linguistics and phonetics. The Language Library. Malden, Massachusetts: Blackwell.

de Blois, Kornelis Frans. 1970. The augment in Bantu languages. Africana linguistica IV. 85-165. Tervuren.

Giles, Howard and Nikolas Coupland. 1991. Language: contexts and consequences. Mapping social psychology. Milton Keynes: Open University Press.

Greenberg, Joseph Harold. 1978. How does a language acquire gender markers? Universals of human language. Vol. 3: word structure, ed. by Joseph Harold Greenberg, Charles A. Ferguson, and Edith A. Moravcsik, 47-82. Stanford: Stanford University Press.

Guthrie, Malcolm. 1948. The classification of the Bantu languages. International African Institute. London, New York: International African Institute and Oxford University Press.

Klamroth, Martin. 1910-11. Beiträge zum Verständnis der religiösen Vorstellungen der Saramo im Bezirk Daressalam. Deutsch-Ostafrika Zeitschrift fur Kolonialsprachen 1-3. 118-53.

Kühl, Karoline H. and Kurt Braunmüller. 2014. Stability and divergence in language contact: An extended perspective. Stability and divergence in language contact : factors and mechanisms, ed. by Kurt Braunmüller, Steffen Höder, and Karoline H. Kühl, 13-38. Amsterdam, Philadelphia: John Benjamins.

Languages of Tanzania Project. 2009. Atlasi ya Lugha za Tanzania. Dar es Salaam: Mradi wa Lugha za Tanzania, Chuo Kikuu cha Dar es Salaam.

Larsen, Amund B. 1993. Naboopposisjon - knot, ed. by Ernst Håkon Jahr, Ove Lorentz \& Marit Christoffersen. Reprinted in Historisk språkvitenskap: Historical linguistics 97-109. Oslo: Novus.

Last, Joseph T. 1886. Grammar of the Kaguru language, eastern equatorial Africa. London: Society for promoting Christian knowledge (SPCK).

Legère, Karsten. 2005. Preprefix or not - that is the question. Studies in African Linguistic Typology, ed. by Erhard Friedrich Karl Voeltz, 251-262. Amsterdam, Philadelphia: John Benjamins.

Legère, Karsten. 2010. Swahili vs. English in Tanzania and the political discourse. Studies of the Department of African Languages and Cultures 44. 47-66.

Lewis, M. Paul. (ed.). 2009. Ethnologue: Languages of the World. Sixteenth edition. Dallas, Texas: SIL International.

Lukanza, R., C. Sengo, M. Nitu and R. Kibeku. 2001. Hadithi za Kilughuru. In Pioneer Bible Translators and Word for the World. ed., 9.

Marten, Lutz. 2003. Dynamic and pragmatic partial agreement in Luguru. Typologie des langues d'Afrique et universaux de la grammaire 1. 113-139.

Marten, Lutz and Malin Petzell. 2016. Linguistic variation and the dynamics of language documentation: Editing in 'pure' Kagulu. Language Documentation and Conservation 10. 105-129.

Marten, Lutz and D. Ramadhani. 2001. An overview of object marking in Kiluguru. SOAS working papers in linguistics and phonetics 11. 259-275.

Mkude, Daniel. 1974. A study of Kiluguru syntax with special reference to the transformational history of sentences with permuted subject and object. London: University of London.

Mkude, Daniel. 2011. The impact of Swahili on other languages in Tanzania. North-South contributions to African languages xi, ed. by Christina Thornell and Karsten Legère, 127-135. Köln: Rüdiger Köppe Verlag.

Morrison, Michelle Elizabeth. 2011. A reference grammar of Bena. 2 volumes. Rice University. 
Nurse, Derek. (ed.). 1970s. A phonological and morphological sketch of 15 of the principal languages of Tanzania. Pages. Dar es Salaam: Institute of Kiswahili Research. IKR, University of Dar es Salaam.

Nurse, Derek and Thomas J. Hinnebusch. 1993. Swahili and Sabaki: a linguistic history. University of California publications in linguistics. Vol. 121. Berkeley: University of California Press.

Nurse, Derek and Gérard Philippson. 1975. The north-eastern Bantu languages of Tanzania and Kenya: a tentative classification. Kiswahili 45(2). 1-28.

Nurse, Derek and Thomas Spear. 1985. The Swahili: reconstructing the history and language of an African society, 800-1500. Ethnohistory series. Philadelphia: University of Pennsylvania Press.

Petzell, Malin. 2008. The Kagulu language of Tanzania: grammar, texts and vocabulary. Cologne: Rüdiger Köppe Verlag.

Petzell, Malin. 2012a. The linguistic situation in Tanzania. Moderna språk 106 Uppsala: Riksförbundet för lärarna i moderna språk. 136-144.

Petzell, Malin. 2012b. The under-described languages of Morogoro - a sociolinguistic survey. The South African Journal of African Languages 32. African Language Association of Southern Africa and the Foundation for Education. 17-26.

Petzell, Malin. 2013 Språklig stigmatisering i Tanzanias skolor. ASLA:s skriftserie 24 Språk $i$ undervisning. 83-92.

Petzell, Malin and Lotta Aunio. Forthcoming. A grammatical sketch of Kami. The Bantu Languages, ed. by Koen Boeston and Mark van de Velde, second edition. Routledge.

Rubagumya, Cashmir M. 1990. Language in Tanzania. Language in education in Africa: a Tanzanian perspective, ed. by Cashmir M. Rubagumya, 5-14. Clevedon. UK: Multilingual Matters Inc.

Schadeberg, Thilo C. 2003. Historical linguistics. The Bantu languages, ed. by Derek Nurse and Gérard Philippson, 143-163. London \& New York: Routledge.

Seidel, August. 1898. Grammatik der Sprache von Irangi nebst Wörterverzeichnis: Grundriß der Wa-Ruguru-Sprache. Die mittleren Hochländer des nördlichen Deutsch-OstAfrika, ed.by Waldermar C. Werther, 387-489. Berlin: Paetel.

SPCK. 1894. Zinyimbo:. "Hymns for Public Worship" in Kimegi. London: Society for Promoting Christian Knowledge.

Trudgill, Peter. 2003. A glossary of sociolinguistics. New York: Oxford University Press.

Wedin, Åsa. 2010. Classroom interaction: Potential or problem? The case of Karagwe. International Journal of Educational Development 30. 145-150.

Van de Velde, M. 2005. The Order of Noun and Demonstrative in Bantu. Studies in African Comparative Linguistics with special focus on Bantu and Mande, ed. by Koen Bostoen and Jacky Maniacky, 425-441. Tervuren: Royal Museum for Central Africa.

Velten, Carl. 1900. Kikami, die Sprache der Wakami in Deutsch-Ostafrika. Mitteilungen des Seminars für orientalische Sprachen, 3: Afrikan Studien. 1-56. 